\title{
Immunological characterisation of an unmasking TB-IRIS case
}

\author{
Katalin A Wilkinson, Graeme Meintjes, Ronnett Seldon, Rene Goliath, Robert J Wilkinson
}

Background. Tuberculosis-associated immune reconstitution inflammatory syndrome (TB-IRIS) is an early complication of combination antiretroviral therapy (cART). Two forms are recognised: (i) paradoxical - recurrent or new TB symptoms develop after cART initiation in patients receiving TB treatment prior to CART; and (ii) unmasking TB-IRIS - active TB presents within 3 months of cART in patients not receiving TB treatment at cART initiation. The latter has heightened clinical manifestations and a marked inflammatory presentation.

Aim. To gain insight into the immune pathogenesis of a case of unmasking TB-IRIS.

Methods. The patient was recruited when starting cART and followed up at 4, 12 and 24 weeks of treatment. Peripheral blood mononuclear cells were used for flow cytometry.

Results. Immunological analysis indicated increased $\mathrm{CD} 4^{+} \mathrm{T}$-cell proportions from $1.1 \%$ at baseline to $14 \%$ at 24 weeks (the CD4 count increased from 4 cells $/ \mu$ at baseline to 41 cells $/ \mu$ at 24 weeks). HIV viral load fell from 460774 to 1405 copies/ml during the same period. The proportion of TB antigen (PPD)-specific CD4 $4^{+} \mathrm{IFN}-\gamma^{+}$ cells increased from $0.4 \%$ at baseline and 4 weeks (IRIS onset) to $7.8 \%$ at 12 weeks (after resolution of the IRIS episode); this fell to $0.7 \%$ at 24 weeks. The surface phenotype of $\mathrm{CD} 4^{+} \mathrm{IFN}-\gamma^{+}$cells during the episode was $\mathrm{CD}^{2} 5 \mathrm{RO}^{+}, \mathrm{CD} 45 \mathrm{RA}$, CCR7, CD62L, $\mathrm{CCR}^{+/-}$and $\mathrm{CD} 69^{-}$. We found a distorted balance between central memory and effector memory T-cells at cART commencement that might have predisposed the patient to unmasking TB-IRIS. We showed that this might have reflected compromised thymic output.

Discussion. While it has been suggested that tuberculin-specific Th1-responses induce TB-IRIS in HIV co-infected patients, our data in this case indicated that these cells were expanded only after IRIS onset and were therefore not inducing TB-IRIS.

Conclusion. We describe, in hitherto unpublished detail, the immunological characterisation of an unmasking TB-IRIS case; we show that thymic output may be compromised at IRIS onset.

S Afr Med J 2012;102(6):512-517
Tuberculosis (TB) is the most common opportunistic infection in HIV-infected people. In 2010 the association between these diseases resulted in up to 1.2 million (12 - 14\%) new TB cases among HIVinfected people and the death of 0.35 million HIV/TB co-infected patients. ${ }^{1}$ The scale-up of combination antiretroviral therapy (cART) in the developing world is rapidly progressing, improving survival of HIV-infected people. While cART effectively reduces TB risk in HIV-infected persons, ${ }^{2}$ TB-associated immune reconstitution inflammatory syndrome (TB-IRIS) has emerged as an important early cART complication, reflecting that TB immune responses contribute to both protection and pathology. Two TB-IRIS forms are recognised: (i) paradoxical, in patients established on TB treatment before cART, who manifest with recurrent or new TB symptoms and clinical features after cART initiation; and (ii) lesser-characterised

Clinical Infectious Disease Research Initiative, Institute of Infectious Disease and Molecular Medicine, University of Cape Town

Katalin A Wilkinson, $\mathrm{PhD}$

Graeme Meintjes, MB ChB, MRCP(UK), FCP(SA), DipHIVMan(SA), PhD Ronnett Seldon, MSc

Rene Goliath, BSc

Robert J Wilkinson, PhD, FRCP

MRC National Institute for Medical Research, London, UK and Department of Medicine, University of Cape Town

Katalin A Wilkinson, $\mathrm{PhD}$

Robert J Wilkinson, PhD, FRCP

Infectious Diseases Unit, G F Jooste Hospital, Cape Town, South Africa, and Division of Medicine, Imperial College London, UK

Graeme Meintjes, MB ChB, MRCP(UK), FCP(SA), DipHIVMan(SA), PhD Robert J Wilkinson, PhD, FRCP unmasking TB-IRIS, in patients not receiving treatment for TB when cART is started, but who present with active TB within 3 months of initiation, with heightened intensity of clinical manifestations, and marked inflammatory features. ${ }^{3,4}$

Recently we studied the regenerating TB-specific T-cell immune responses in Mycobacterium tuberculosis (MTB)-sensitised adults over 12 months following commencement of cART. We showed that, in overall improved TB antigen-specific immunity, it is the central memory T-cell response that best correlates with increased cART-mediated immunity. ${ }^{5}$ A single patient in this cohort excluded from analysis - was diagnosed with overt pulmonary TB having commenced cART. We were therefore presented with the opportunity to undertake detailed immunological analysis of a case that we considered as unmasking TB-IRIS. Tuberculin-specific Th1-responses were expanded during, but not before, the IRIS episode. We found a distorted balance between central memory and effector memory T-cells at cART commencement that might have predisposed the patient to unmasking TB-IRIS.

\section{Methods}

The study was approved by the University of Cape Town Faculty of Health Sciences Human Research Ethics Committee (FHS HREC 336/2004). HIV-infected adults were recruited at G F Jooste Hospital (GFJH), Cape Town, at the start of cART (day 0), and followed up at weeks 2, 4, 12, 24, 36 and 48, as described in detail. ${ }^{5}$ Venous blood (30 $\mathrm{ml}$ ) was obtained at each time-point for separating peripheral blood mononuclear cells (PBMC) and serum.

For comparison in some instances we included a subset of 5 patients ( 3 female, 2 male, median age 36 years, median nadir CD4 count 42), recruited for a previously published prospective longitudinal study; ${ }^{6}$ all developed paradoxical TB-IRIS within a median of 14 days of commencing cART.

T-cell phenotyping was performed using fresh PBMC following overnight stimulation with purified protein derivative (PPD; Statens Serum Institute, Denmark) and staining for various cell-surface 
markers and intracellular cytokines as described, ${ }^{5}$ using a BD FACS Calibur Flow Cytometer. Data analysis was performed using FlowJo Cytometry Analysis software (TreeStar Inc, Stanford University, FlowJo Africa scheme).

Serum thymulin was determined by enzyme-linked immunosorbent assay (ELISA) (PromoKine, PromoCell Gmbh, Germany) according to the manufacturer's recommendations.

Statistical analysis was performed using GraphPad Prism (version 5.0a). Data normality was assessed with the D'Agostino \& Pearson test. Results are quoted as medians with inter-quartile range (IQR).

\section{Results \\ Patient clinical characterisation}

The subject of the current report, one of 28 in our previous study, ${ }^{5}$ was a 34-year-old male diagnosed with HIV infection in 2005 and treated for pulmonary TB in primary care from September 2005 to April 2006. He was referred to GFJH in March 2006 on diagnosis of cryptococcal meningitis, and treated with a 2-week course of amphotericin-B and flucytosine, followed by maintenance fluconazole. In May 2006 he commenced cART and was recruited to our longitudinal study. ${ }^{5}$ His CD4 count prior to cART was 4 cells $/ \mu \mathrm{l}$ and HIV viral load was 460774 copies/ml.

The patient reported no symptoms on the day of commencement of cART: stavudine $30 \mathrm{mg}$ 12-hourly, lamivudine $150 \mathrm{mg}$ 12-hourly and efavirenz $600 \mathrm{mg}$ nocte. He reported no new symptoms and good cART adherence 2 weeks after initiation. However, at week 4 he showed symptoms of active TB: a productive cough, progressive dyspnoea on exertion of 6 days' duration and diarrhoea, $3 \mathrm{~kg}$ of weight loss in 2 weeks (weight $48.5 \mathrm{~kg}$ ), febrile and pale appearance, respiratory distress, and hepatomegaly. A chest radiograph showed bilateral extensive mid-zone infiltrates and right hilar lymphadenopathy. Sputum direct microscopy ( $3+$ acid-fast bacilli) confirmed MTB and the culture was positive (susceptible to rifampicin and isoniazid). He was admitted to GFJH and recommenced on anti-TB therapy (isoniazid, rifampicin, ethambutol, pyrazinamide and streptomycin initially). Corticosteroids were not prescribed. His symptoms resolved within 2 weeks: 12 weeks post cART initiation he weighed $50.5 \mathrm{~kg}$ and his CD 4 count increased to $38 \mathrm{cells} / \mathrm{mm}^{3}$; by 24 weeks his weight increased to $56 \mathrm{~kg}$, his CD4 count to $41 \mathrm{cells} / \mathrm{mm}^{3}$ and his HIV viral load decreased to 1405 copies $/ \mathrm{ml}$.

\section{Immunological characterisation}

Immunophenotyping by flow cytometry was undertaken at day 0 , and 2, 4, 12 and 24 weeks post cART initiation (Table 1). Results are presented as a comparison with the median and IQR values from the 19-patient comparison group previously described. ${ }^{5}$

The patient started cART with a very low CD 4 count $\left(4\right.$ cells $\left./ \mathrm{mm}^{3}\right)$, reflected by the $\mathrm{CD} 4^{+}$T-cell proportions in flow cytometry: $1.1 \%$ of PBMC were positive for $\mathrm{CD} 4$ on day 0 , remaining lower than the median of the comparison group up until 24 weeks, when it became similar at $14 \%$. On the other hand, the proportion of CD8 $8^{+} \mathrm{T}$-cells (\% of PBMC) was comparable to and within the IQR of the comparison group at day 0, 2 and 4 weeks of cART. Interestingly, at 12 weeks (after the IRIS episode) the patient's $\mathrm{CD}^{+} \mathrm{T}$-cell proportions fell to just $27.4 \%$, rising again to $53 \%$ at 24 weeks.

\section{Cellular phenotypes in the peripheral blood}

The proportion of effector $\mathrm{CD} 4^{+} \mathrm{CCR} 5^{+} \mathrm{T}$-cells was relatively high (Table 1): $11.8 \%$ on day 0 , falling to $0.5 \%$ at 4 weeks, and a large expansion to $53.9 \%$ at 12 weeks. These dynamic changes were also reflected in proportional changes of differentiated CD4 cells that lack CD27 and CCR7, expanding to $72.3 \%$ at 12 weeks.
The less differentiated central memory cells, as assessed by 2 combinations of cell surface markers, expanded earlier at 4 weeks of cART (the time of IRIS onset): $\mathrm{CD} 4{ }^{+} \mathrm{CD} 27^{+} \mathrm{CD} 45 \mathrm{RA}-$ to $78.2 \%$ and $\mathrm{CD} 4{ }^{+} \mathrm{CD} 27^{+} \mathrm{CCR} 5$ to $71.4 \%$. After IRIS resolution at 12 weeks, these cells had proportionally and sharply declined to 14.7 and 13\%, respectively, well below the median observed in the comparison group.

The least differentiated $\mathrm{CD} 27^{+} \mathrm{CD} 45 \mathrm{RA}^{+} \mathrm{CD} 4^{+}$T-cells were proportionally elevated at cART initiation $(27 \%$ at day 0 , double the $13.1 \%$ median of the comparison group) and fell to $2.9 \%$ at week 4 (IRIS onset). This was followed by a slow increase to $6.9 \%$ at week 12 and a large expansion to $42 \%$ at week 24 .

Cellular activation was increased in the patient's blood from day 0 , with $\mathrm{CD}^{+}{ }^{+} \mathrm{CD} 69^{+}$cells reaching a peak of $19.4 \%$ at 4 weeks (IRIS onset), remaining elevated at week 12 (10.7\%), and declining to levels similar to the comparison group by week 24 (Table 1). Similarly, $\mathrm{CD} 4^{+} \mathrm{CD} 25^{+} \mathrm{T}$-cells were proportionally elevated at weeks $4(3.8 \%)$ and $12(6.6 \%)$, with a further increase to $9.9 \%$ at week 24 . The proportion of $\mathrm{CD} 4{ }^{+} \mathrm{CD} 25^{+} \mathrm{T}$-cells expressing interleukin (IL)-10 (regulatory cells) was slightly elevated from the start of cART and increased to $5.3 \%$ at 12 weeks, compared with the almost undetectable levels in the comparison group throughout the longitudinal follow-up.

\section{PPD-specific cytokine-producing T-cells during IRIS}

Effector function of the $\mathrm{CD} 4^{+} \mathrm{T}$-cells, determined by intracellular cytokine staining for IFN $-\gamma$ in response to PPD stimulation, was found to be only $0.4 \%$ at cART initiation, remaining at similar levels at weeks 2 and 4 (when IRIS was diagnosed). However, there was an increase to $7.8 \%$ at week 12 , in line with the expansion of effector $\mathrm{CD}^{+}{ }^{+} \mathrm{CCR}^{+}{ }^{+}$and terminally differentiated effector $\mathrm{CD} 4{ }^{+} \mathrm{CD} 27$ CCR7- T-cells. The proportion of PPD-specific CD4 $4^{+} \mathrm{IFN}-\gamma^{+}$T-cells returned to $0.7 \%$ at 24 weeks of cART, within the range seen in the 19 unaffected patients (comparison group). Staining for CD45RO indicated that these cells were of memory phenotype (Table 1).

Further surface phenotype analysis of the expanded CD $4^{+} \mathrm{IFN}-\gamma^{+}$ T-cells at 12 weeks showed CD45RA, CCR7, CD62L, CCR5 ${ }^{+/}$and CD69- (Fig. 1). Staining for additional cytokines indicated that $\mathrm{CD}^{+}{ }^{+}$cells positive for the IL-2, IL-10 and TNF were all expanded at week 12 to $7.7 \%, 8.9 \%$ and $8.5 \%$, respectively. CD $4{ }^{+} \mathrm{IL}-2^{+}$cells were proportionally elevated at week 4 (4.8\%, compared with the $0.3 \%$ median in the comparison group), in line with the central memory CD4 T-cell expansion. Moreover, the cytokine-positive $\mathrm{CD} 4{ }^{+} \mathrm{T}$-cells displayed a poly-functional phenotype by expressing different combinations of IL-2, TNF and IL-10 (Fig. 2). CD4 $4^{+} \mathrm{TNF}^{+}$ T-cells were proportionally elevated in the patient's blood from the time of cART initiation (1.6\%), indicating a distinct inflammatory component (Table 1).

\section{Distorted balance between CD4 memory phenotypes}

The overall dynamics of CD4 T-cell phenotypes indicated that, between cART initiation and IRIS onset, the central memory T-cells proportionally and rapidly increased and effector T-cells proportionally fell, leading to a distorted balance between T-cell phenotypes. The ratio between the 2 subsets $\left(\% \mathrm{CD}^{+} \mathrm{CD} 27^{+} \mathrm{CD} 45 \mathrm{RA} / \% \mathrm{CD}^{+}{ }^{+} \mathrm{CCR}^{+}\right.$ cells)(Fig. 3A) indicated a rise from 1.1 at day 0 to 156 at week 4 (IRIS onset), and a fall to 0.3 at 12 weeks (after IRIS resolution). The comparative median ratios in the comparison group were relatively stable over time (7, 7.2 and 9.7 at weeks 0,4 and 12, respectively).

The least differentiated $\mathrm{CD} 27^{+} \mathrm{CD} 45 \mathrm{RA}^{+} \mathrm{CD} 4^{+}$T-cells were proportionally over-represented in the patient's blood at cART initiation (27\%), compared with the 19 patients who did not develop 
Table 1. Cellular phenotyping by flow cytometry in the peripheral blood of the unmasking TB-IRIS case*

\begin{tabular}{|c|c|c|c|c|c|c|}
\hline & & \multicolumn{5}{|c|}{ Duration of cART } \\
\hline \multicolumn{2}{|c|}{ Proportion of PBMC (\%) } & Day 0 & Week 2 & Week $4^{\ddagger}$ & Week $12^{\S}$ & Week 24 \\
\hline \multirow[t]{2}{*}{$\mathrm{CD}^{+}$} & Median & $8.3(2-12)$ & $10.9(6-15)$ & $10.5(8-15)$ & $9.5(8-15)$ & $14.4(9-22)$ \\
\hline & Case & $1.1^{\dagger}$ & 1.3 & 3.6 & 2.2 & 14.5 \\
\hline \multirow[t]{2}{*}{$\mathrm{CD}^{+}$} & Median & $55(39-61)$ & $56(42-66)$ & $54(46-68)$ & $51(40-65)$ & $56(48-63)$ \\
\hline & Case & 46.1 & 46.9 & 59.3 & 27.4 & 53.4 \\
\hline \multirow[t]{2}{*}{$\mathrm{CD}^{+}{ }^{+} \mathrm{CCR} 5^{+}$} & Median & $5.8(3-11.9)$ & $5.7(4.1-15.2)$ & $5.2(2.1-23)$ & $5.1(3-13.4)$ & $4.5(1.2-5.8)$ \\
\hline & Case & 11.8 & 7.3 & 0.5 & 53.9 & 2.0 \\
\hline \multirow[t]{2}{*}{$\mathrm{CD}^{+} \mathrm{CD} 27^{-\mathrm{CCR}} 7^{-}$} & Median & $42.9(22-84)$ & $36.6(22-46)$ & $39.3(20-66)$ & $33.7(18.5-57)$ & $23.2(15-39)$ \\
\hline & Case & 69.1 & 57.4 & 32.8 & 72.3 & 21.0 \\
\hline \multirow[t]{2}{*}{$\mathrm{CD}^{+} \mathrm{CD} 27^{+} \mathrm{CD} 45 \mathrm{RA}^{-}$} & Median & $40.6(18-49)$ & $40.6(23-49)$ & $37.4(27-56)$ & $49.5(35-61)$ & $45.0(39-60)$ \\
\hline & Case & 12.9 & 27.7 & 78.2 & 14.7 & 38.8 \\
\hline \multirow[t]{2}{*}{$\mathrm{CD} 4^{+} \mathrm{CD} 27^{+} \mathrm{CCR} 5^{-}$} & Median & $60.4(25-81)$ & $58.2(37-81)$ & $61.8(32-77)$ & $64.2(32.5-74)$ & $74.6(58.5-80)$ \\
\hline & Case & 27.2 & 43.1 & 71.4 & 13.0 & 76.6 \\
\hline \multirow[t]{2}{*}{$\mathrm{CD}^{+} \mathrm{CD} 27^{+} \mathrm{CD} 45 \mathrm{RA}^{+}$} & Median & $13.1(7.4-23.1)$ & $15.9(8.6-33.6)$ & $14.4(7.3-36)$ & $11.1(4.1-20.5)$ & $22.6(9-36)$ \\
\hline & Case & 27.0 & 25.2 & 2.9 & 6.9 & 42.2 \\
\hline \multirow[t]{2}{*}{$\mathrm{CD}^{+}{ }^{+} \mathrm{CD} 69^{+}$} & Median & $1.7(1.5-3.9)$ & $1.6(0.9-2.6)$ & $1.4(1.1-1.9)$ & $1.8(1.3-4.9)$ & $1.4(1.2-1.8)$ \\
\hline & Case & 6.3 & 4.8 & 19.4 & 10.7 & 0.5 \\
\hline \multirow[t]{2}{*}{$\mathrm{CD} 4^{+} \mathrm{CD} 25^{+}$} & Median & $2.3(0.9-6.6)$ & $3.6(1.7-5.4)$ & $1.1(0.5-2.6)$ & $3.1(1.4-5.1)$ & $1.3(0.9-2.6)$ \\
\hline & Case & 2.1 & 2.4 & 3.8 & 6.6 & 9.9 \\
\hline \multirow[t]{2}{*}{$\mathrm{CD}_{4}{ }^{+} \mathrm{CD} 25^{+} \mathrm{IL} 10^{+}$} & Median & $0.1(0.03-0.3)$ & $0.1(0.03-0.11)$ & $0.1(0.02-0.2)$ & $0.1(0.03-0.2)$ & $0(0.02-0.1)$ \\
\hline & Case & 0.9 & 0.9 & 0.2 & 5.3 & 0.03 \\
\hline \multirow[t]{2}{*}{$\mathrm{CD}^{+}{ }^{+} \mathrm{IFN}^{-} \gamma^{+}$} & Median & $0.9(0.3-1.4)$ & $0.8(0.5-1.3)$ & $0.6(0.3-1.4)$ & $0.5(0.3-0.9)$ & $0.4(0.2-0.9)$ \\
\hline & Case & 0.4 & 0.4 & 0.4 & 7.8 & 0.7 \\
\hline \multirow[t]{2}{*}{$\mathrm{CD}^{+} \mathrm{IFN}^{-} \gamma^{+} \mathrm{CD} 45 \mathrm{RO}^{+}$} & Median & $0.5(0.1-0.7)$ & $0.3(0.1-0.9)$ & $0.4(0.2-0.6)$ & $0.4(0.1-1.1)$ & $0.2(0.1-0.9)$ \\
\hline & Case & 0.3 & 0.7 & 0.3 & 7.9 & 0.7 \\
\hline \multirow[t]{2}{*}{$\mathrm{CD}^{+} \mathrm{IL}^{+}$} & Median & $0.4(0.8-1.3)$ & $1.1(0.3-4.1)$ & $0.3(0.2-1.0)$ & $0.4(0.2-0.9)$ & $0.2(0.1-0.6)$ \\
\hline & Case & 0.7 & 2.8 & 4.8 & 7.7 & 0.4 \\
\hline \multirow[t]{2}{*}{$\mathrm{CD} 4^{+} \mathrm{IL} 10^{+}$} & Median & $0.4(0.2-0.8)$ & $0.6(0.2-3.1)$ & $0.4(0.3-0.8)$ & $0.4(0.3-0.9)$ & $0.2(0.1-0.5)$ \\
\hline & Case & 2.1 & 3.1 & 5.1 & 8.9 & 0.4 \\
\hline \multirow[t]{2}{*}{$\mathrm{CD}^{+} \mathrm{TNF}^{+}$} & Median & $0.3(0.2-1.1)$ & $0.3(0.1-1.2)$ & $0.4(0.2-0.8)$ & $0.5(0.3-1.1)$ & $0.2(0.1-1.0)$ \\
\hline & Case & 1.6 & 1.4 & 1.0 & 8.5 & 0.8 \\
\hline $\begin{array}{l}\text { Expressed as \% specific cell type } \\
\text { Values in bold indicate those par } \\
\text { IIRIS onset. } \\
\text { After IRIS resolution. }\end{array}$ & $\begin{array}{l}\text { ed with the } \mathrm{n} \\
\text { sthat fall outs }\end{array}$ & $\begin{array}{l}\text { an (IQR) of a previously- } \\
\text { of the IQR of the median }\end{array}$ & $\begin{array}{l}\text { cribed 19-patient compa } \\
\text { ues observed in the com! }\end{array}$ & $\begin{array}{l}\text { group. } \\
\text { son group. }\end{array}$ & & \\
\hline
\end{tabular}

TB during the first year of cART (Table 1). We hypothesised that this could be due to increased T-cell turnover as a result of decreased thymic output, as previously suggested. ${ }^{7}$ Thymic output can be approximated through the ratio of naive/memory T-cells. ${ }^{8}$ We found the ratio of percentage $\mathrm{CD} 4{ }^{+} \mathrm{CD} 27^{+} \mathrm{CD} 45 \mathrm{RA}^{+} / \mathrm{CD} 4{ }^{+} \mathrm{CD} 27^{+} \mathrm{CD} 45 \mathrm{RA}$ to be 2.1 at baseline (compared with median 0.3 in the comparison group) and 0.04 at 4 weeks (IRIS onset) (Fig. 3B).

For further investigation, an alternative method of quantifying thymic output was employed. Thymulin (formerly called serum thymic factor) is a nonapeptide hormone secreted by human thymic epithelial cells and is essential for T-cell differentiation. ${ }^{9}$ Its production is stimulated by prolactin and growth hormones and it is detectable in serum by ELISA. ${ }^{10}$ The serum thymulin concentration in 13/19 patients with no adverse events during cART was higher (median 406 $\mathrm{pg} / \mathrm{ml}$, IQR 356 - 507) than that of the unmasking TB-IRIS patient at week 4 (223 pg/ml; Fig. 4A).

We confirmed this finding by determining serum thymulin concentrations in 5 patients, previously recruited for a prospective longitudinal analysis, ${ }^{6}$ all of whom developed paradoxical TB-IRIS within 14 days of cART commencement. We found significantly lower serum thymulin concentrations in TB-IRIS patients at the time of IRIS compared with baseline levels (Fig. 4B): $382 \mathrm{pg} / \mathrm{ml}$ (IQR $323-441 \mathrm{pg} / \mathrm{ml}$ ) at day 0 v. $316 \mathrm{pg} / \mathrm{ml}$ (IQR $248-386 \mathrm{pg} / \mathrm{ml}$ ) at day 14 ( $p=0.03$, Wilcoxon-matched pairs test). Further comparison of the 19-patient group with no adverse events (representing protective immune reconstitution) with the group with TB-IRIS (representing 


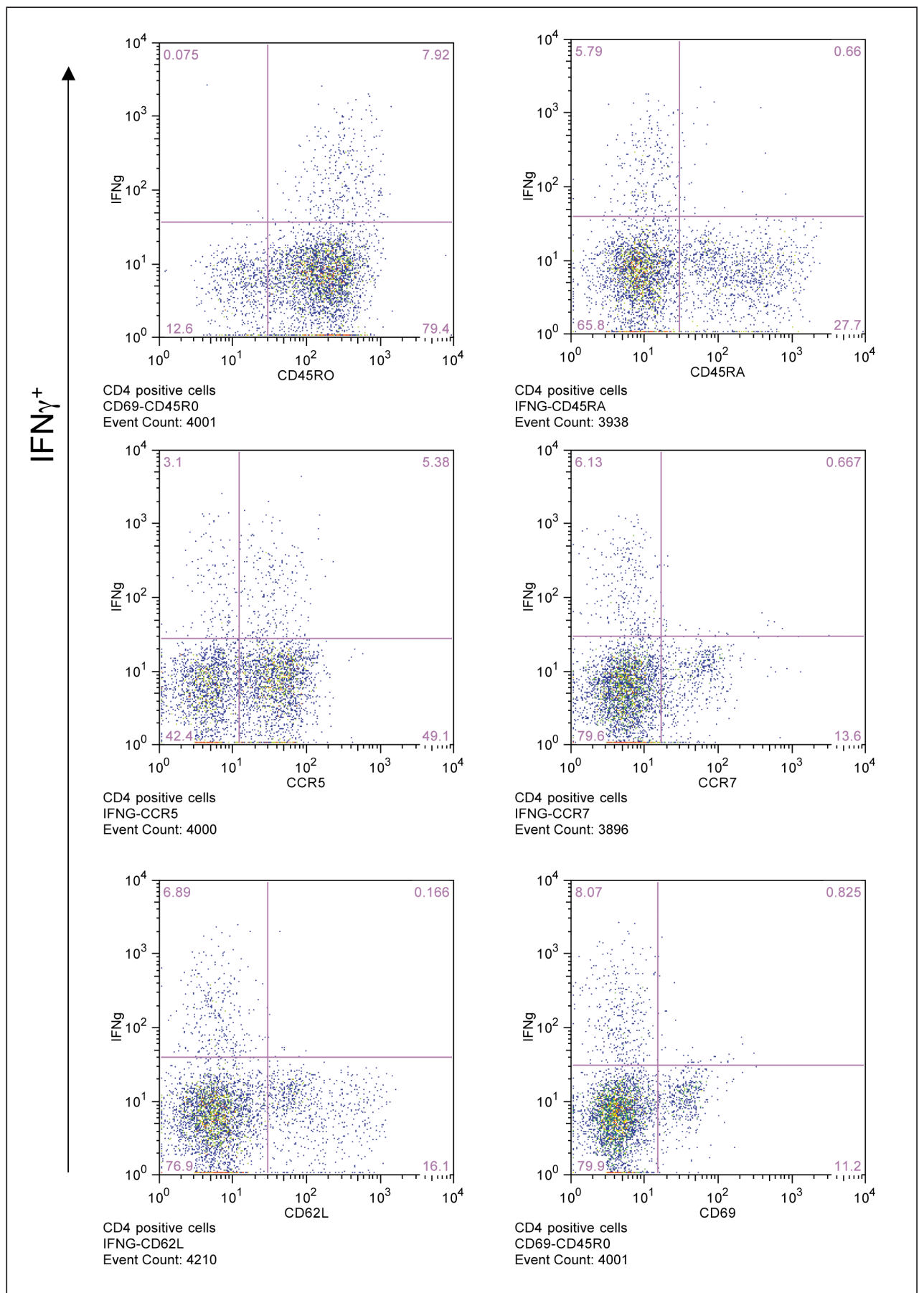

Fig. 1. Flow cytometry plots illustrating the surface phenotype of CD4+IFN- $\gamma^{+}$cells at 12 weeks of cART (8 weeks after IRIS onset). $C D 4^{+}$lymphocytes were selected and gated on intracellular IFN- $\gamma$ (y-axes) and the surface markers CD45RO, CD45RA, CCR5, CCR7, CD62L and CD69 (illustrated on the $x$-axes).

pathogenic immune reconstitution) indicated that, while there was no difference in thymulin concentrations at baseline ( $p=0.23$, day 0 ), there was a significant difference between the groups at IRIS onset ( $p=0.009$, day 14). Overall, these data indicate that thymic output may be significantly compromised at IRIS onset.

\section{Discussion}

TB is the most common opportunistic infection in HIV-infected patients in Africa and reaches its highest incidence within the first 3 months of cART commencement. It has been proposed that all TB diagnosed when ART is concurrent should be termed ART-associated TB. ${ }^{11}$ However, TB that presents soon after ART initiation due to restoration of TB antigenspecific immune responses has been termed 'unmasking TB', and a subset of these patients presenting with heightened clinical manifestations within the first 3 months of ART are regarded as having 'unmasking TB-IRIS'. 'There have been less cases of unmasking TB-IRIS reported compared with paradoxical TB-IRIS, due to difficulties in diagnosis. It is accepted that TB-IRIS is a clinical syndrome resulting from the exaggerated inflammatory response towards the antigens of MTB in the context of a recovering immune response. However, the immunopathogenesis of this immune reaction is less well understood.

Although the immunopathogenesis of paradoxical TB-IRIS has been related to the expansion of PPD-specific IFN- $\gamma$-secreting CD4 T-cells during cART, we described similar CD4 T-cell expansions in TB-IRIS and non-IRIS control patients, bringing into question the causality of these expansions. ${ }^{6}$

The present case presented a unique opportunity to elucidate further the immunopathogenesis of unmasking TB-IRIS. Our data show that the PPD-specific IFN- $\gamma$-secreting CD4 T-cells expanded after resolution of the IRIS episode (at 12 weeks, when the patient improved).

T-cells undergo a unique developmental programme after activation, resulting in the generation of memory and effector T-cells. The sequence of differentiation remains unclear in humans but telomere length supports a linear pathway. ${ }^{12}$ Macaque studies also support the linear differentiation pathway from naïve, to central memory, to effector memory, with terminally differentiated cells representing the end stage. ${ }^{13}$ Our data show a relatively large proportion of undifferentiated CD4 T-cells at the time of cART initiation, leading on to the expansion of central memory cells at 4 weeks, and subsequent expansion of effector and terminally differentiated effector cells at 12 weeks. This coincides with the expansion of effector function (cytokine secretion) with intracellular 
staining being highest for all 4 cytokines studied (IFN- $\gamma$, IL-2, IL-10 and TNF) at 12 weeks. The Th1 expansions associated with this case of unmasking TB-IRIS appear to be a consequence of the syndrome, and possibly due to the distorted proportional balance between memory T-cell phenotypes at the time of staring cART. Only the blood compartment was studied in this patient; therefore, we cannot exclude that the distorted balance is not attributed to sequestration in mycobacterial infection sites.

It is widely accepted that patients with high viral loads and low CD4 counts are at the highest risk of developing all forms of TB-IRIS. ${ }^{2,11}$ Studies of T-cell dynamics during HIV infection have shown that the higher the viral load, the greater the rate of CD4 T-cell destruction, hence the requirement for immune system reconstitution; this is dependent on the reconstitution of naïve CD4 T-cells, which in turn depends on thymic output. ${ }^{7}$ HIV-infected patients receiving cART and undergoing protective immune reconstitution, show a progressive increase in naïve $\mathrm{T}$-cell numbers related to thymic function. ${ }^{14}$ A quantitative measure of thymic function is achieved by assaying the nonapeptide hormone thymulin produced by thymic epithelial cells. ${ }^{9}$ HIV-infected individuals show a progressive decline of circulating thymulin levels. ${ }^{15}$ Here we show that the serum thymulin concentration was higher in patients with protective immune reconstitution, compared with this unmasking TB-IRIS case, especially at the time of IRIS diagnosis. We further confirmed in a larger group of patients with pathogenic immune reconstitution that thymic function is significantly compromised at the time of IRIS onset, as reflected by lower serum thymulin concentrations. Serum thymulin concentration in patients at highest risk for developing TB-IRIS warrants further study. 0 and 14 of cART.

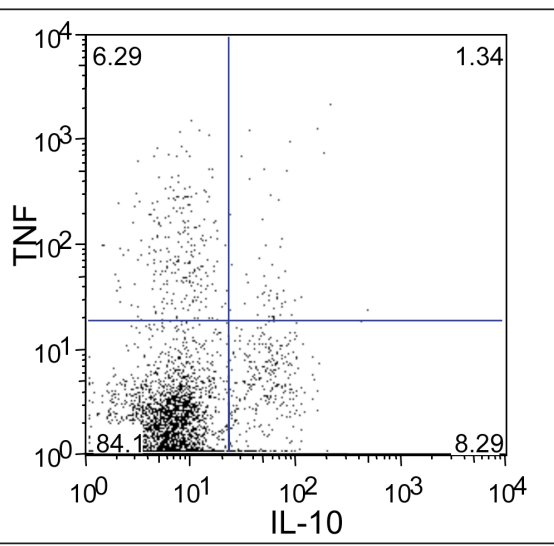

Fig. 2. Flow cytometry plots illustrating the intracellular cytokine-secreting phenotype of $C D 4^{+}$cells at 12 weeks of cART (8 weeks after IRIS onset). CD4+ lymphocytes were selected and gated on intracellular cytokines IL-2, TNF and IL-10.

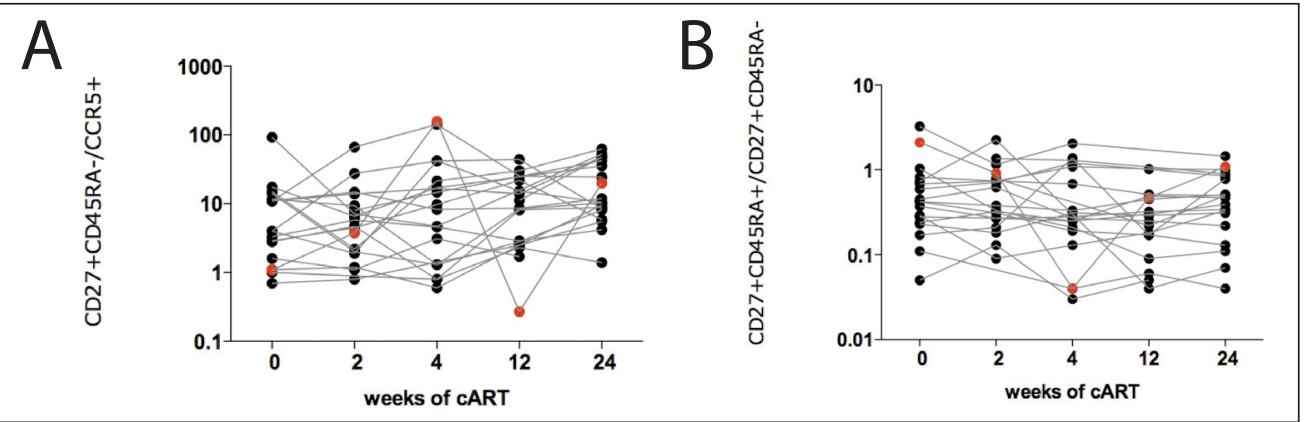

Fig. 3. Evaluation of the ratio between $(A)$ central memory and effector cells as calculated by percentage $C D 4^{+} C D 27^{+} C D 45 R A \%$ $C D 4^{+} C C R 5^{+}$cells for each patient; and (B) naïve and memory cells calculated by percentage $C D 4^{+} C D 27^{+} C D 45 R A^{+}$/ $C D 4^{+} C D 27^{+} C D 45 R A-$ for each patient. The unmasking TB-IRIS case is illustrated in red.

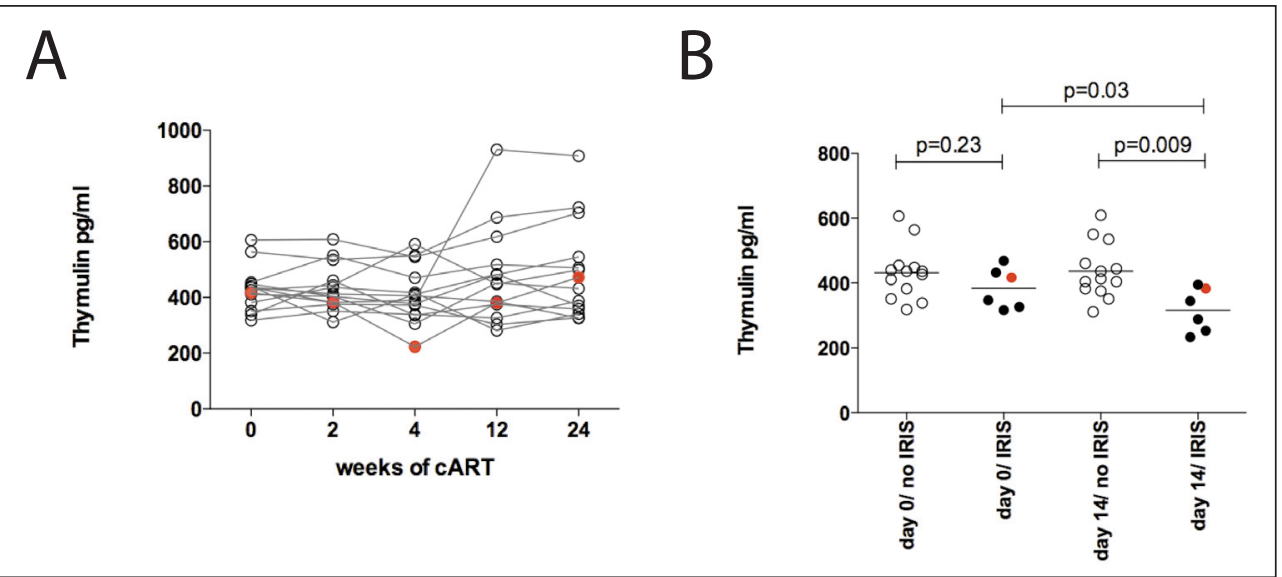

Fig. 4. (A) Longitudinal evaluation of serum thymulin concentration in 13 patients with no adverse events during cART (open circles) compared with the unmasking TB-IRIS case (illustrated in red). (B) Comparison of the same 13 patients (no IRIS, open circles) with 5 paradoxical TB-IRIS patients (IRIS, black circles) and the unmasking TB-IRIS case (red) at day

There are several limitations to our study: (i) the absence of MTB culture at the end of the initial course of TB treatment to confirm treatment success, (ii) the lack of viral load at timepoints other than at day 0 and 6 months of cART, and (iii) the lack of longitudinal follow-up beyond 6 months. However, the marked inflammatory component, as illustrated by the expansion of activation and inflammatory markers (CD69 and TNF) on CD4 T-cells, supports the diagnosis of unmasking TB-IRIS in our study. 


\section{Conclusion}

We describe, in hitherto unpublished detail, the immunological characterisation of an unmasking TB-IRIS case, showing that immune changes may be linked to the distorted homeostatic balance between T-cell memory phenotypes at the time of cART initiation. We provide evidence that this distorted balance may reflect compromised thymic output in patients who are most at risk of developing immune reconstitution disease.

Acknowledgements. We acknowledge Priscilla Mouton for her involvement in patient recruitment and follow-up. KAW is funded by the MRC-UK. RJW and GM are funded by the Wellcome Trust, London, UK (WT 084323, 088316, 081667). GM received SATBAT research training and was funded by the Fogarty International Center and NIH (NIH/FIC U2RTW007373-01A1 and U2RTW007370-01A1).

\section{References}

1. World Health Organization (WHO). Global tuberculosis conrtrol; WHO report. Geneva: WHO, 2011. http://www.who.int/tb/publications/global_report/en/ (accessed 12 June 2011).

2. Badri M, Wilson D, Wood R. Effect of highly active antiretroviral therapy on incidence of tuberculosis in South Africa: a cohort study. Lancet 2002;359:2059-2064.

3. Meintjes G, Lawn SD, Scano F, et al. Tuberculosis-associated immune reconstitution inflammatory syndrome: case definitions for use in resource-limited settings. Lancet Infect Dis 2008;8:516-523.
4. Meinties G, Rabie H, Wilkinson RJ, Cotton MF. Tuberculosis-associated immune reconstitution inflammatory syndrome and unmasking of tuberculosis by antiretroviral therapy. Clin Chest Med 2009;30:797-810.

5. Wilkinson KA, Seldon R, Meinties G, et al. Dissection of regenerating T-cell responses against 5. Wilkinson KA, Seldon R, Meintjes G, et al. Dissection of regenerating T-cell responses against
tuberculosis in HIV infected adults with latent tuberculosis. Am J Respir Crit Care Med 2009;180:674tuberculosis in HIV infected adults with latent tuberculosis. Am J Respir Crit Care Med 2009;180:674-

6. Meintjes G, Wilkinson KA, Rangaka MX, et al. Type 1 helper T-cells and FoxP3-positive T-cells in HIV-tuberculosis-associated immune reconstitution inflammatory syndrome. Am J Respir Crit Care Med 2008;178:1083-1089

7. Douek DC, Betts MR, Hill BJ, et al. Evidence for increased T-cell turnover and decreased thymi output in HIV infection. J Immunol 2001;167:6663-6668.

8. Lavi RF, Kamchaisatian W, Sleasman JW, et al. Thymic output markers indicate immune dysfunction in DiGeorge syndrome. J Allergy Clin Immunol 2006;118:1184-1186.

9. Bach JF, Dardenne M. Thymulin, a zinc-dependent hormone. Med Oncol Tumor Pharmacother 1989;6:25-29.

10. Dardenne M, Savino W, Berrih S, Bach JF. A zinc-dependent epitope on the molecule of thymulin, a thymic hormone. Proc Natl Acad Sci USA 1985;82:7035-7038.

11. Lawn SD, Wilkinson RJ, Lipman MC, Wood R. Immune reconstitution and "unmasking" of tuberculosis during antiretroviral therapy. Am J Respir Crit Care Med 2008;177:680-685.

12. Appay V, van Lier RA, Sallusto F, Roederer M. Phenotype and function of human T lymphocyte subsets: consensus and issues. Cytometry A 2008;73:975-983.

13. Pitcher CJ, Hagen SI, Walker JM, et al. Development and homeostasis of T-cell memory in rhesus macaque. J Immunol 2002;168:29-43.

14. Franco JM, Rubio A, Martinez-Moya M, et al. T-cell repopulation and thymic volume in HIV-1 infected adult patients after highly active antiretroviral therapy. Blood 2002;99:3702-3706.

15. Rafie C, Campa A, Smith S, et al. Cocaine reduces thymic endocrine function: another mechanism fo accelerated HIV disease progression. AIDS Res Hum Retroviruses 2011;27:815-822. 